\title{
Smart Citizens in the Hackable City: On the Datafication, Playfulness, and Making of Urban Public Spaces Through Digital Art
}

\author{
Michiel de Lange ${ }^{1(\bowtie)}$, Kåre Synnes ${ }^{2}$, and Gerald Leindecker ${ }^{3}$ \\ ${ }^{1}$ Utrecht University, Utrecht, The Netherlands \\ m. 1.delange@uu.nl \\ ${ }^{2}$ Luleå University of Technology, Luleå, Sweden \\ Kare.Synnes@ltu.se \\ ${ }^{3}$ Institut für Strukturentwicklungsplanung, Wels, Austria \\ office@iapl.eu
}

\begin{abstract}
This contribution explores concepts, approaches and technologies used to make urban public spaces more playful and artful. Through a variety of compelling narratives involving play and art it assists in the design of new cyberparks, public spaces where digitally mediated interactions are an inherent part. How can play and interactive art be used to strengthen urban public spaces by fostering citizen engagement and participation? We propose to not only utilise interactive media for designing urban (public) spaces, but also for social innovation for the benefit of citizens. in cyberparks. The contribution connects urbanity, play and games, as well as concepts of active and passive interactive digital art as part of trends towards pervasive urban interaction, gameful design and artification. We position this as an important part of developing humancentred smart cities where social capital is central, and where citizens engaging in play and art are prerequisites for sustainable communities. Using art, play and games to foster citizen engagement and collaboration is a means to develop social technologies and support the development of collective intelligence in cyberparks. This is studied in concrete cases, such as the Ice Castle in Luleå, Sweden and the Ars Electronica in Linz, from a multi-disciplinary stance involving interaction design, digital art, landscape design, architecture, and health proficiencies. We will analyse two cases of gameful design and one case of digital interactive art being used to address urban issues. Rezone the game is an interactive multimedia game developed to tackle vacancy in the city of Den Bosch in the Netherlands. The Neighbourhood is a board game developed to involve various stakeholders in making their neighbourhood using water as a collective resource.
\end{abstract}

Keywords: Playful city - Games - Interactive art - Civic participation · Smart city

Parts of this chapter were drawn from de Lange (2015).

(C) The Author(s) 2019

C. Smaniotto Costa et al. (Eds.): CyberParks, LNCS 11380, pp. 157-166, 2019.

https://doi.org/10.1007/978-3-030-13417-4_13 


\section{Introduction}

This contribution addresses the question of how urban media digital media technologies can help citizens to gain more ownership of their environment. How can digital data, game and new forms of creativity and art make the city hackable, that is, open to systemic changes by 'smart' city-makers?

Digital media technologies have become increasingly intertwined with everyday urban life. One only has to think of mobile interfaces, wireless networks and protocols, GPS navigation, smart cards, camera surveillance, sensors, a large number of large and small screens, big data and smart algorithms present in today's cities. Such digital media technologies affect the spatial use and design, social situations and behaviour in our everyday urban life, and affect how we work, travel, live, spend our free time and meet each other. This interweaving of digital and physical worlds is the starting point for so-called 'smart city' policy and design agendas (see for example Hollands 2015). Municipalities, technology companies and knowledge institutions use smart technologies to try to more efficiently organize urban processes and solve problems such as energy and water supply, transport and logistics, health, safety and well-being, air and environmental quality. The hope is that this improves the quality of life of people and city governance. This is a commendable endeavour. However, there are a number of more critical aspects about such visions.

In the first place, the term smart lacks definition and precision. Who or what are actually 'smart' in smart cities? Often it isn't the people for whom all those high-tech solutions are being devised. Take, for example, emblematic greenfield developments like Masdar City in the Arab Emirates and New Songdo in South Korea, smart cities planned on the drawing board in the first decade of the 21 st century. In these visions, smart citizens do not have an active role in shaping their living environment. They are allowed to live in an envisioned high-tech utopia designed by companies and city governments for them, not with or by them. By contrast, already existing cities such as Rio de Janeiro, Barcelona or Amsterdam tend to take care of this differently. Here, the role of the municipal government is much more pronounced, and attempts are made to allow people to play a much more active role. Still, the question remains: smart city, for and by whom?

A second point of criticism is the underlying idea of cityness. The emphasis on efficiency is rather unilateral. The smart city conjures up modernist images of control, efficiency and control. As a vision on urban future it is rather totalizing and offers a generic template with little space for local and cultural differences. Similar to the 'creative city' visions popular two decades ago, as a type of city marketing the smart city offers quite a superficial narrative. Which city does not want to be creative or smart? The smart city denies the messy and unpredictable improvisation character make cities charming and exciting places. This messiness fosters creativity and innovation and is the pedagogical foundation for learning to coexist with others in increasingly super-diverse urban society.

Thirdly, the vision of technology as a solution machine is problematic. Many issues in this complex world are extremely complex, challenging and 'wicked' (Rittel and Webber 1973). It is naive to think that solutions come from purely technological 
interventions. What's more, technologically driven solutions may have side-effects that counteract initial aims or produce perverse effects. For example, smart parking apps that show free parking places in real-time makes car mobility as a system more attractive. The more complex underlying issue of how urban societies can deal with questions of traffic and mobility remains untouched. This example shows how technological solutions may in effect undermine the public debate about what kind of city we actually want with each other. In addition, the question arises what role we think commercial platforms should play in the current reshuffling of individual, collective and public interests. How desirable is outsourcing decision-making power to computerized systems in which algorithms make the decisions? 'Smart' urban technologies reinforce trends that can be labelled as the logics of the three C's logic: consumption (commercialization of urban public space), control (increased surveillance in public spaces), and capsularisation (retreat in secure private spaces while being in public) (de Lange and de Waal 2013).

In this light, it is hopeful that a growing number of cities look for future scenarios that do not focus so much on smart technologies but on smart urban residents. In this contribution, we look for these human-centred stories about the smart city. These stories are variegated but all entail people-centric perspectives on what makes a city 'smart' as well as 'just'. This way, we can find answers to the question of how we can provide more humane directions to the future of the city under the influence of digital technologies and media culture.

\section{The Data City}

There is great enthusiasm about the potential to deploy big data urban for monitoring and controlling a range of urban processes (see for example Goldsmith and Crawford 2014). Predominantly, it is companies and governments that use data to this end. In addition, data also represent potential social value. Opening up datasets and doing useful things with these data can be a way to make this value publicly available. Meanwhile, urban residents too are currently measuring, quantifying and visualizing all kinds of aspects of everyday life thanks to the emergence of mobile media and sensors such as the Fitbit and iWatch, and popular mobile apps like Runkeeper and Strava.

Somewhere in between institutional data and personal quantified self-data, we can discern collective data initiatives. In many places all over the world, urban residents with sensors and networked technologies are busy generating data about, for example, air quality. People thus form a public that works in a networked way on issues that are of common interest to them (Gabrys 2014). Examples of this from the Netherlands are Sensornet, a noise pollution project around Schiphol Airport (http://geluidsnet.nl), and Urban AirQ, a project involving urban residents in measuring air quality (https://waag. org/en/project/urban-airq). Remarkable in the Dutch context is that oftentimes civil society organizations take the initiative to act as a link between the so-called triple helix of citizens, companies and governments.

The role of data in the smart city is often presented as a government management tool and business intelligence tool for companies. Governments and companies are using data and dashboards to make decisions. The municipality of Amsterdam for 
instance works with various data sources and dashboards in areas such as housing, public health, tourist flows and energy consumption (https://data.amsterdam.nl). Important questions include: What do we get to know about the city, and what not? What translations will take place when data are linked together? And how does that direct decisions in, and about, policy and management?

The data city suggests that cities can be approached as complex systems that can be known and managed based on data and rules for rational decision making. We may wonder to what extent data represent or construct reality? For example, crime maps can affect our perceptions of certain neighbourhoods, and strengthen self-fulfilling tendencies. It is likely that people, as well as law-enforcement, will experience and behave differently in neighbourhoods known as dangerous. An exciting question is how data and dashboards, in addition to rationalized control and transparency, can also contribute to affective experiences of the city, serendipity, creative expressions, and collective interventions. Can we use data to tell other appealing stories about (the future of) the city?

\section{The Playful City}

Another narrative is that of the playful city. The relationship between cities and play goes a long way back. The city has traditionally been a centre for entertainment, a stage for everyday role play and drama, a place for playful learning and for subversive ludic actions. Moreover, city simulations have been around for decades. The rise of mobile technologies in the city combined with game culture offers opportunities to involve people in playful ways with the city. Play and games can be used to involve people in the planning process, with specific urban issues, to encourage meeting with strangers and other ways of urban space use, or to allow people to temporarily allow urban space. A Dutch example is Play the City, which offers a playful method to allow various stakeholders to discuss the future of the city in a game setting and through game dynamics (http://playthecity.eu). Indeed, architects and urban planners are turning to games and play to shift the way they work on designing cities.

Play and games appeal to different audiences, like young people, who do not come to town hall discussion evenings. Play and games offer horizons for action. In safe environments players can experiment and practice without serious consequences. Some game types provide insight into rules, procedures and parameters; others encourage players to develop team-based strategies and build trust. Ranging from competition, strategy, role play to agility games, play and games appeal to creativity, innovation capacity, learning ability and social self-organization of people. This seems a promising way to address and further strengthen citizen smartness. In free spaces, new imaginaries of the future city are created.

Nevertheless, the scenario of the playful city also raises more critical questions about, among other things, the exploitation of free labour under the guise of play, known under the portmanteau 'playbour' (Kücklich 2005). Players are usually not paid but they do provide valuable input. Other thorny issues concern the 'spectacularisation' of the urban public realm in the current experience economy, and the extent to which governments and other institutional parties take seriously the outcomes of playful 
interventions and commit themselves to firmly and sustainably anchor this in policy. Moreover, simplistic 'gamification' of urban public space through external reward mechanisms itself undercuts the autotelic quality of play itself and risks instrumentalising social interactions (Alfrink 2015).

\section{Case Rezone the Game, Playing Against Vacancy ${ }^{1}$}

At this point we take a look at a concrete case, in order to see how participatory smart citizenship may work in practice. Rezone the Game is a project to help address the complex urban issue of vacancy ${ }^{2}$. Two cultural organizations from Den Bosch in the Netherlands, the Bosch Architecture Initiative and art organization Wave of Tomorrow, collaborated with a game design school to create Rezone the Game (www.rezone.eu), challenging players to 'fight blight'. In the game, players work together to keep the city safe from deterioration by salvaging real estate from decline. There are four player roles: the proprietor (owner of real estate), mayor (representing the municipality), engineer (urban designer) and citizen (neighbours). Rezone the Game is composed of a physical board game with a number of 3D printed iconic buildings that represent the neighbourhood, an augmented reality layer of real-time information about these buildings projected on a screen, and a computer algorithm programmed to let buildings descend into vacancy like a wildfire. A camera above registers the players' moves by scanning QR codes on pawns. The game engine continually adapts to changes. To beat the system players must strategically collaborate instead of pursuing self-interests. The game was tested during a series of events like The Playful Arts Festival (2013), and Rezone Playful Interventions (2014), with among others the mayor of Den Bosch playing. Major Dutch construction company Heijmans became interested. Their involvement started a new collaboration and lead to a follow-up game concept. Part of the motivation for the development of Rezone the Game was that it is hard to address complex questions like vacancy through conventional means. Traditional parties involved in urban development are not inclined to invest in initiatives with uncertain outcomes and wait for others to take the first step. In a game, it was believed, stakeholders would feel freer to experiment without immediate (financial) consequences.

This game informs the three elements for a human-centred smart city that have been mentioned in the introduction: smartness, the role of technologies in civic participation, and the notion of cityness. A 'playful civic smartness' is strengthened in various ways. Players have to manage their different stakeholder roles, they must forge coalitions with other players and quickly negotiate, they must unpack the underlying mechanisms of vacancy and think of ways to address this issue. Rezone the Game involves all of the play types identified by French philosopher Roger Caillois: competition, role-playing, chance, and even dizzying speedy interactions with the computer system. The competitive element exists not between players but between players and the system (Caillois 2001). Playing together forges trust and connections between players.

\footnotetext{
1 This case description is based on de Lange (2019).

${ }^{2}$ De Lange has been involved in this project as a paid advisor and researcher.
} 
Real world stakeholders can meet each other in a playful atmosphere instead of at the negotiation table. The game is fun and acts as a catalyst for ensuing discussions and reflections among players (a crucial part of the play sessions), and even potential follow-ups. It is a deliberately simplified artificial safe setting where real emotions and preferences emerge. It invites people to temporarily stand in adversaries' shoes. This could lead to better understanding of mutual standpoints through embodied experience and affect, instead of mere argumentation and deliberation. No longer passive users of the city players temporarily become smart planners.

Rezone the Game helps to foster citizen engagement with the issue of vacancy. The game was used to invite real world stakeholders around the table. This happened during special play sessions and events such as the Playful Arts Festival (2012) and Rezone Playful Interventions event (2013). Stakeholders met in a joyous atmosphere instead of tense town hall meetings or around the negotiation table. Playing together allowed relationships to form based on trust. Importantly, Rezone the Game is not a 'solutionist' attempt to solve a complex urban problem via technology. Playing the game helps people to become incentivized and take ownership for an otherwise abstract issue like vacancy. Playing makes the issue tangible through personal lived experience and provides possible horizons for action. The game mechanics and dynamics are deliberately aimed at stimulating social interactions and experimentation with collective action. Hence, we can conclude that this playful intervention strengthens a new hybrid liberal/communal type of citizenship: people's individual rights to the city are extended into a collective right to the smart city.

Furthermore, Rezone the Game represents a particular take on the notion of cityness. A superficial reading might suggest that it is a game that helps to solve the issue of vacancy. The underlying notion of cityness in such a view, would be one of a playable system with citizens as productive problem-solvers. In this view, a complex urban problem can have an optimal solution, which leads the city into a state of equilibrium. By contrast I understand the game to actually have a deeper narrative, which tells that urban issues like vacancy are far too complex to model, let alone solve, by simple technological means. We suggest that the special quality of playful urban interventions like Rezone the Game is that they act on a meta-level. Gregory Bateson famously theorized that play always consists of a level of meta-communication. When monkeys in the zoo engage in play-fighting they exchange signals that say that it is not actually to be understood as fighting. In his words, we face "two peculiarities of play: (a) that the messages or signals exchanged in play are in a certain sense untrue or not meant; and (b) that that which is denoted by these signals is nonexistent" (Bateson 1972/1987: 141). This is precisely the strength of playful city interventions like Rezone the Game: it questions its own solutionist promise by signalling to not actually do what it purports to do (solving vacancy). Instead, the game impels players to stake claims about what kind of city they actually want, to negotiate the underlying issue, and to agree on how to address it collectively. This involves a view of the city as a commons, a space of perpetual tension and conflict and at the same time a space that allows for negotiation and collaboration (Foster and Iaione 2016: 288).

Understanding city life in terms of play and games stands in a long tradition (de Lange 2015). Arguably, this connection is becoming even more important today. An increasing number of people grow up playing games as part of their cultural repertoire. 
They are 'ludo-literate': knowledgeable about how games work and what you can do with them. We live in a playful media culture in which we are continuously surrounded by a plethora of technologies that offer spaces for playful experimentation and shape our understanding of the world as playful (Frissen et al. 2015). Playing means acquiring knowledge about the world and the capacity to act in it. Therefore, truly human centred smart cities should be playful cities.

\section{The Interactive Art City}

The narrative of interactive art in the city looks at urban life from the perspective of art and culture. While the city of art has a long history - ranging from urban design-shape masterpieces like the city of Palmanova or Brasilia to the support of public spaces and squares by artefacts of art like the Capitol square in Rome as well as symbols (Leindecker and Duschlbauer 2003) and the intellectual concept of the city of art (Calvino 1972) - the new layer of interactive digital media art in urban public space is only recently evolving.

Digital Media Art in public space has started with small interventions, and the domain was mainly initiated from computer science. It is understood as the crosssection of interaction with the spectators and auditors with new concepts of multimedia art. This mandate attracted the art scene as a whole, since it is part of the concept of art to reflect on society and how to deal with the technology challenge. A fine example of this movement can be demonstrated by the Ars Electronica in Linz (Austria). The yearly festival along the river Danube and the park along the classical music hall using digital information to create a new form of space in relation with contemporary art including music, light, digital information and live performance. The highlight of the event, that is organised similar to a fair with a Prix Ars Electronica competition, lectures and interactive digital art, is a public event, first held in 1979, where there is a free public performance using various media disciplines to perform. This single event attracts yearly up to 50.000 spectators, that become also parameters for the interaction and can partly interfere with the performance on predefined parameters. In 2016 it was the flight of coordinated 100 drones in direct relation and interaction with the visual sound- cloud of the concert.

\section{The Maker City}

Another narrative looks at urban dwellers as creative makers of their own life world. In order to understand this urban 'maker culture', we must look not only at the technology but also at associated cultural practices and institutional arrangements. People today use a wide variety of digital tools, like computers, semi-professional software, and 3D printers, to design and develop new products and services. In addition, there exists a cultural norm and practice to share this work online with others. Open standards, licenses and platforms allow people to exchange and edit home-made files and offer their own work. According to some therefore, we are living in the era of a 'third 
industrial revolution' (Anderson 2012). After the mechanization and automated mass production, the time supposedly has come in which consumers are producers and everyone is a maker.

Many cities harbour so-called fablabs, hackerspaces, repair cafes, and hackathons: indoor places where people 'do it themselves', often with the help of others. In addition to these so-called maker spaces, there is a rich set of urban interventionist practices, mostly outdoors on the streets. Often these interventions are organized through social media, with catchy labels like urban acupuncture and tactical urbanism. Characteristic is their temporary nature and sometimes subversive appropriation of public urban space, often stemming from the desire to counter dominant discourses and practices of commercialization, control, and cocooning in urban spaces.

Here too we see an interesting semi-institutionalized intermediate form in the socalled 'urban labs', or 'living labs'. These are designated innovation spaces for creative experimentation, with less rules and more open frameworks. An example of such an urban laboratory is the Buiksloterham district in Amsterdam North, where home buyers could purchase their own lots and develop their own sustainable living space.

The maker city draws our attention to shared 'ownership' issues in processes of urbanization, participation culture, and "the right to the city". However, this narrative also has a downside. Some people argue that digital work in a platform economy leads to a downward spiral, a race to the bottom of precarious labour where people tend to outcompete each other for ever cheaper rates. Others point to the underlying neo-liberal ethics that formulates citizenship increasingly in terms of entrepreneurship and productivity. The good citizen in the participation society manages her own business, takes care of her neighbour, and thus generates savings and social profits.

\section{Conclusion: Towards a Hackable City?}

A common line in the different stories discussed above is the capacity for change that city inhabitants have. Smart citizens take care of the future of their city. Seen in this light, we can speak of the city that is 'hackable' (de Waal, et al. 2017; de Lange and de Waal 2019). This term refers to the many similarities between original hackers (computer hobbyists who wrote their own software for existing machines and shared code with each other and the world) and contemporary do-it-yourself city makers, who also provide incremental and open innovations for the city using limited resources. With digital media they can bend, circumvent, or initiate all kinds of urban infrastructures, systems and services. We can see this cooperative way of city making at work in a range of domains. For instance, in self-building, joint sensing of air quality, and the organization of collective services from insurance to energy generation to healthcare. The hackable city is the nexus where the production and management of valuable resources in the data city joins the personal imagination and social drive of the playful city and the creative do-it-yourself character of the maker city (Fig. 1). 


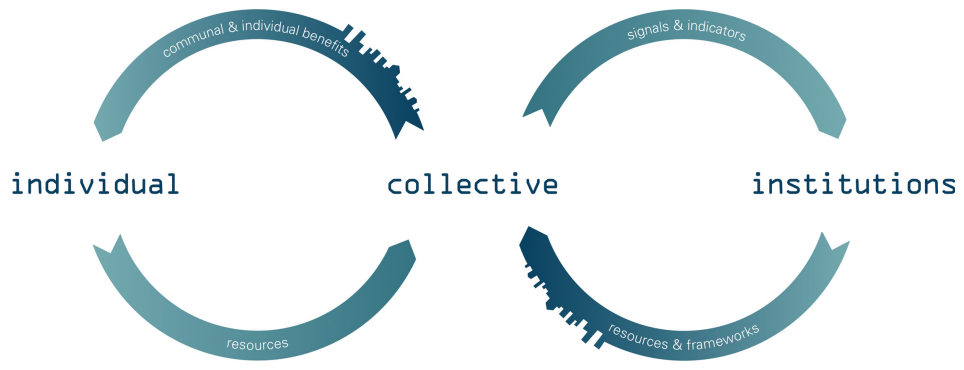

Fig. 1. The hackable city model, source: www.thehackablecity.nl

The figure above provides insight into the dynamics between individual attitude and drive, collective practice and exchange, and the system world of rules and infrastructures. It shows how an individual ethics of self-reliance can be connected to collective practices of knowledge sharing and exchange of resources. Reciprocity is crucial here. The model also shows how collective interests relate to institutional frameworks. For example, self-building groups should make plausible arguments for their approach, which can convince institutional stakeholders to change their frameworks. The notion of 'hacking' is provocative. For some, it evokes associations with computer criminality, but its productive value lies in providing possible answers to questions about the use of digital media for issues of public interest and for empowering smart citizens to become involved in their cities. The truly smart city is a hackable city.

\section{References}

Alfrink, K.: The Gameful City. In: Walz, S.P., Deterding, S. (eds.) The Gameful World: Approaches, Issues, Applications, pp. 527-560. The MIT Press, Cambridge (2015)

Ampatzidou, C., Bouw, M., van de Klundert, F., de Lange, M., de Waal, M.: The Hackable City: A Research Manifesto and Design Toolkit. Amsterdam Creative Industries Publishing, Amsterdam (2015)

Anderson, C.: Makers: The New Industrial Revolution, 1st edn. Crown Business, New York (2012)

Bateson, G.: Steps to an Ecology of Mind; Collected Essays in Anthropology, Psychiatry, Evolution, and Epistemology, 1987th edn. Chandler Pub. Co., San Francisco (1972)

Bogost, I.: Persuasive Games: The Expressive Power of Videogames. The MIT Press, Cambridge (2007)

Caillois, R.: Man, Play, and Games. University of Illinois Press, Urbana/Chicago (2001)

Calvino, I.: The Invisible City, 1st edn. Giulio Einaudi Editor, Italy (1972)

van Dijck, J., Poell, T., de Waal, M.: The Platform Society: Battle for Public Values in an Online World. University Press, Amsterdam (2016)

Foster, S.R., Iaione, C.: The City as a Commons. Yale Law Policy Rev. 34(2), 280-349 (2016)

Frissen, V., Lammes, S., de Lange, M., de Mul, J., Raessens, J. (eds.): Playful Identities: The Ludification of Digital Media Cultures. Amsterdam University Press, Amsterdam (2015) 
Gabrys, J.: Programming environments: environmentality and citizen sensing in the smart city. Environ. Plan. D: Soc. Space 32(1), 30-48 (2014)

Goldsmith, S., Crawford, S.: The Responsive City: Engaging Communities Through Data-Smart Governance. Jossey-Bass, San Francisco (2014)

Hollands, R.G.: Critical interventions into the corporate smart city. Camb. J. Reg. Econ. Soc. 8(1), 61-77 (2015)

Kücklich, J.: Precarious playbour: modders and the digital games industry. Fibrecult. J. 5 (2005). http://fijive.fijibreculturejournal.org/fcj-025-precarious-playbour-modders-and-the-digitalgames-industry

de Lange, M.: The playful city: citizens making the smart city. In: Glas, R., Lammes, S., de Lange, M., Raessens, J. (eds.) The Playful Citizen: Power, Creativity, Knowledge. Amsterdam University Press, Amsterdam (2019)

de Lange, M.: The playful city: using play and games to foster citizen participation. In: Skaržauskienè, A. (ed.) Social Technologies and Collective Intelligence, pp. 426-434. Mykolas Romeris University, Vilnius (2015)

de Lange, M., de Waal, M. (eds.): The Hackable City: Digital Media and Collaborative City-Making in the Network Society. Springer, London (2019)

de Lange, M., de Waal, M.: Owning the city: new media and citizen engagement in urban design, waves, bits \& bricks: media and the social production of urban space. First Monday 18 (2013)

de Waal, M., de Lange, M., Bouw, M.: The hackable city: citymaking in a platform society. Arch. Des. 87(1), 50-57 (2017)

Leindecker, G., Duschlbauer, T.: The tower and the evil - a cultural retrospective of a symbol. In: Clavaron, Y., Dieterle, B. (eds.) La Memoire des villes, pp. 323-334. Universität Saint Etienne, Saint Etienne (2003)

Rittel, H.W.J., Webber, M.M.: Dilemmas in a general theory of planning. Policy Sci. 4, 155-169 (1973)

Schouten, B., Ferri, G., de Lange, M., Millenaar, K.: Games as strong concepts for city-making. In: Nijholt, A. (ed.) Playable Cities: The City as a Digital Playground, pp. 23-45. Springer, London (2016). https://doi.org/10.1007/978-981-10-1962-3_2

Sicart, M.: Playin' the city: artistic and scientific approaches to playful urban arts. Navig. J. Media Cult. Stud. 16(1), 25-40 (2016)

Open Access This chapter is licensed under the terms of the Creative Commons Attribution 4.0 International License (http://creativecommons.org/licenses/by/4.0/), which permits use, sharing, adaptation, distribution and reproduction in any medium or format, as long as you give appropriate credit to the original author(s) and the source, provide a link to the Creative Commons license and indicate if changes were made.

The images or other third party material in this chapter are included in the chapter's Creative Commons license, unless indicated otherwise in a credit line to the material. If material is not included in the chapter's Creative Commons license and your intended use is not permitted by statutory regulation or exceeds the permitted use, you will need to obtain permission directly from the copyright holder.

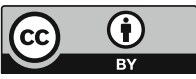

